\title{
O manuscrito do Catálogo do Colégio Jesuítico de Santo Alexandre em Belém do Grão-Pará (1720) da Coleção Lamego do arquivo do Instituto de Estudos Brasileiros da Universidade de São Paulo (IEB-USP)
}

Renata Maria de Almeida Martins ${ }^{1}$

\section{Introdução}

O Catalogo deste Colégio de Santo Alexandre, seos bens, officinas, fazendas, servos, gados, dispendios e dividas activas e passivas ${ }^{2}$ (fig. 01) foi publicado, pela primeira vez ${ }^{3}$, em versão incompleta, por Alberto Frederico de Morais Lamego (1870-1951) que adquiriu o manuscrito na Eu-

I Doutoranda da Faculdade de Arquitetura e Urbanismo da Universidade de São Paulo (FAU-USP), na área de História e Fundamentos da Arquitetura e Urbanismo, orientada pelo Prof. Dr. Luciano Migliaccio, bolsista de Doutorado CNPq desde 2005, com período de estágio em Roma, Itália, 2007 (Doutorado Sandwich, Università Degli Studi di Napoli l’Orientale, Nápoles, Itália).E-mail: renatamartins@usp.br

2 Agradecemos ao Prof. Dr. István Jancsó por ter disponibilizado a documentação digitalizada (IEB-USP, 2005). Segundo nossos estudos, veremos que o Catálogo na verdade pertence ao ano de 1720 . A transcrição do mesmo foi realizada em conjunto com o nosso orientador de doutorado, Prof. Dr. Luciano Migliaccio, e publicada parcialmente no apêndice de artigo apresentado no Simpósio Arquitetura e Documentação, realizado em Belo Horizonte em setembro de 2008. Ver MARTINS, Renata; MEDRANO, Ricardo. Por uma história da arquitetura e das artes nas missões jesuíticas do Maranhão e Grão-Pará: documentação primária inédita e documentação fotográfica. In: Seminário Latino-Americano Arquitetura e Documentação. Belo Horizonte, setembro de 2008. CD-ROM. [Neste trabalho, a autora apresentou pesquisa realizada com documentação primária e o coautor apresentou levantamento fotográfico realizado a partir destes estudos.]. Ver também MARTINS, Renata; MIGLIACCIO, Luciano. Fontes primárias para a história da arquitetura e da arte nas missões jesuíticas da Amazônia: a Igreja de São Francisco Xavier e o Colégio de Santo Alexandre no Catálogo de 1720 e no Inventário de 176o. In: XII Jornadas Internacionales Misiones Jesuiticas: intereacciones y sentidos de la conversión. Buenos Aires, setembro de 2008. CD-ROM.

3 Lamego, Alberto Frederico de Morais. A Terra Goytacá a luz de documentos inéditos. 4 v. Paris: L'Édition d'Art, 1913. 
ropa para sua coleção Brasiliana ${ }^{4}$. O padre jesuíta Serafim Leite, maior historiador da Companhia de Jesus no Brasil, cita Lamego ${ }^{5}$ em seus estudos $^{6}$, e também transcreve e publica outros trechos do Catálogo $^{7}$, cuja fotocópia consultou no Arquivo da Província Portuguesa.

Em 1935, a coleção foi adquirida pelo governo de São Paulo, recomendada por Mário de Andrade, e entregue à guarda da Faculdade de Filosofia, Ciências e Letras (FFLCH) da recém-fundada Universidade de São Paulo (USP) ${ }^{8}$. Em 1968, a Coleção Lamego foi transferida para o Instituto de Estudos Brasileiros (IEB-USP) que, em 2002, microfilma os documentos e publica o Inventário analítico da Coleção (cerca de 4.062 manuscritos) ${ }^{9}$ onde localizamos o Catálogo $^{10}$.

Como Leite não examinou o original, e tanto ele quanto Lamego não publicaram a transcrição integral, há divergências quanto à datação do Catálogo. Leite acredita que o documento seja de cerca de 1718 e, no catálogo do IEB, a data aproximada é 1710. Porém, durante leitura de trecho não transcrito pelos dois historiadores, constatamos que o Catálogo foi, na verdade, escrito em 1720. No capítulo sétimo, intitulado "Dos esculptores, pedreiros e carpinteiros", extraímos a seguinte citação "A 1- oficina conforme seu inventário pertencem [segue lista de ferramentas]. Deste ano de 1720 e comprei mais 167 peças de toda casta para os ditos ofícios"11. No título do capítulo 11oㅡ encontra-se a seguinte referência: "Das despesas e receitas deste Colégio com várias [?] desde 1715 até $1720 . . . " 12$.

4. Para consultar a biografia de Alberto Lamego e a história de sua coleção Brasiliana, ver ELLIS, Myriam. Apresentação à primeira edição. In: BELOTTO, Heloísa; HUTTER, Lucy; NOGUEIRA, Arlinda. Catálogo de manuscritos da Coleção Alberto Lamego. São Paulo: Instituto de Estudos Brasileiros da Universidade de São Paulo, 2002. p. 13-19.

5 LAMEgO, Alberto. A Terra Goytacá a luz de documentos inéditos, 8 v. Bruxelas / Niterói: s/e, 1923-1947.

6 LEITE, Serafim. Arte e ofícios dos jesuitas no Brasil (I549-I760). Lisboa/Rio de Janeiro: Brotéria/Edições de Portugal, 1953; e LEITE, Serafim (S. J.). História da Companhia de Jesus no Brasil [1938], t. III e t. IV. São Paulo: Edições Loyola, 2004.

7 LEITE, Serafim. Arte e oficios dos jesuitas no Brasil (I549-I760). op. cit., p. 23-26.

8 MARX, Murillo. Apresentação. In: BELOTTO, Heloísa; HUTTER, Lucy; NOGUEIRA, Arlinda. op. cit., p. o9-10.

9 BelotTo, Heloísa; HUTTER Lucy; NOGUEIRA, Arlinda. op. cit.; e também ELLIS, Myriam. Catálogo da miscelânia e dos manuscritos da Coleção Lamego. In: Separata da Revista de História, n. 46, São Paulo, 1961, p. $5^{21}$.

10 CATÁLOGO deste Colégio de Santo Alexandre, seus bens, oficinas, fazendas, servos, gados, dispêndios, e dívidas activas e passivas. [ca. 1710], o8 p. In: Coleção de manuscritos de Alberto Lamego. São Paulo: Instituto de Estudos Brasileiros da Universidade de São Paulo (IEB-USP), 2002, documento 1.320, códice 43-113, p. 107. Agradeço ao Prof. Dr. István Jancsó por disponibilizar a documentação digitalizada (2005).

11 MANUSCRito DO CATÁLOGO deste Colégio de Santo Alexandre, seus bens, oficinas, fazendas, servos, gados, dispêndios, e dívidas activas e passivas. [ca. 1710], 8 p., documento 1.320, códice 43-113, p. 04 .

12 Ibidem, p. 06. 
Não sabemos de quem teria sido a autoria do Catálogo, mas, segundo Leite ${ }^{13}$, o Catálogo era privativo do Colégio, pois, diferentemente daqueles que eram enviados à Cúria Generalíssima em Roma, também contém informações sobre índios e negros que faziam parte do "pessoal" do Colégio e não apenas de padres e irmãos jesuítas.

A Igreja e o Colégio da Companhia de Jesus em Belém foram inaugurados entre os anos de 1718 e 1719, ou seja, pouco antes do Catálogo ter sido escrito. Daí o valor deste documento, pois muito pode nos dizer da aparência da igreja, somente um ou dois anos após sua inauguração. Como veremos, o Catálogo delineia a arquitetura dos edifícios, trazendo informações sobre capelas, altares, pinturas e esculturas, além de nomes de escultores, pedreiros e carpinteiros índios. Inclui também, informações sobre os bens pertencentes ao Colégio, sacristia, "capela da comunidade", livraria, botica, cozinha e "officinas", e ainda a relação de despesas e receitas do Colégio de Santo Alexandre.

Portanto, este trabalho tem como objetivo apresentar nossa transcrição e nossos estudos sobre o conteúdo integral do Catálogo, visando responder algumas questões sobre a arquitetura e a ornamentação da Igreja e do Colégio de Belém, especialmente fazendo ligações com o acervo ainda remanescente.

\section{Critérios}

Para a transcrição do manuscrito, não utilizamos normas paleográficas ${ }^{14}$, apenas tentamos transcrever o texto de forma a se tornar coerente para leitura nos dias atuais. Nem sempre conseguimos transcrever todas as palavras do Catálogo, faltando-nos um maior conhecimento sobre o português do século XVIII. Acrescentamos algumas notas explicativas e inserimos, quando pertinente, a paginação original do $C a$ tálogo no texto. Quando não foi possível a leitura, indicamos no lugar da palavra não identificada um ponto de interrogação entre colchetes: [?]. Acreditamos que especialistas em paleografia possam, a partir desta publicação, fazer uma transcrição mais completa. Importava-nos aqui, especialmente, os trechos referentes à arte e à arquitetura.

13 LEITE, Serafim. Arte e ofícios dos jesuitas no Brasil (I549-I760). op. cit., p. 26, nota 1.

14 Agradecemos à Profa. Dra. Yedda Dias Lima (IEB-USP) pela oportunidade de assistir às aulas do curso de Paleografia como ouvinte (2005). 


\section{Os treze capítulos que formam o Catálogo}

Capitulo 1o: Dos bens deste Colégio;

Capítulo 2o: Da sacristia e do que lhe pertence;

Capítulo 3o: Da capela da comunidade dedicada ao São Borja;

Capítulo 4: Da livraria;

Capítulo 5o: Da rouparia e botica que se acham juntas, por falta de lugar;

Capítulo 6o: Da despensa, refeitório e cozinha;

Capítulo 7o: Dos escultores, pedreiros e carpinteiros;

Capítulo 8: Dos muros da cerca que de novo fizeram de pedra e cal;

Capítulo 9o: De um cubículo debaixo da livraria para guardar o que pertence aos padres que vão para as missões $e$ fazendas;

Capítulo 10: Dos oficiais que tem o Colégio;

Capítulo 11:. Das despesas e receitas deste Colégio com várias [?] desde 1715 até 1720 do que consta das contas para [?] deve particulares como se vê no dito fl. 105;

Capítulo 12-: Das dívidas expressas destes anos a pessoas de fora não satisfeitas falando do que ainda resta de dividas antigas não satisfeitas.

Capítulo 13o: Das dividas que devem ao Colégio.

\section{A Igreja de São Francisco Xavier e o Colégio de Santo Alexandre no Catálogo de 1720: arquitetura e ornamentação}

"É este Colégio formado em figura quadrada, sito na melhor parte da cidade e sobre a praça [Praça Frei Caetano Brandão] e mar [Rio Guamá, Baía de Guajará]"15, assim inicia o Catálogo do Colégio de Santo Alexandre. A construção em quadra foi o partido arquitetônico mais adotado pelas ordens religiosas e empregado também pela Companhia de Jesus, como nos diz Lúcio Costa no texto pioneiro A arquitetura dos

15 MANUSCRITO DO CATÁLOGO. op. cit., p. ol. 
jesuitas no Brasil ${ }^{16}$ : “dispor os vários corpos da construção em quadra, como então se dizia, formando-se assim um ou mais pátios, foi mantido também pelos jesuítas."17 Além do Colégio de Belém, são também dispostos em quadra o Colégio da Bahia, o de Olinda, os do Espírito Santo e do Rio de Janeiro, o do Embu e o de Paranaguá ${ }^{18}$.

Segundo o Catálogo, no capítulo 1o "Dos bens deste Colégio", no ano de 1720 a Igreja de São Francisco Xavier já possuía sua capela-mor profunda, cujo acesso ao altar-mor era dado por cinco degraus ${ }^{19}$, como ainda hoje podemos atestar. (fig. 02)

No altar-mor (fig. 02), também identificamos os dois "cardencios", ou melhor, nichos, citados no Catálogo ${ }^{20}$. Neste período, as telas que ornamentavam as laterais da capela ainda não existiam e, sim, "quatro tribunas e dois nichos cada um de sua parte" ${ }^{21}$.

Atestamos a presença da "cornija mestra que cinge toda a igreja"22, além do cruzeiro e das "capelas fundas"23, que nada mais são do que as duas capelas do transepto. Porém, o Catálogo não descreve seus altares ou retábulos e nem diz a quais santos estas capelas foram sagradas.

Portanto, a Igreja de São Francisco Xavier, inaugurada entre 1718 e 1719, obviamente já possuía planta de nave única com duas capelas do transepto e seis capelas colaterais. Quanto às capelas laterais, o Catálogo cita apenas três: "Tem mais a dita Igreja de mais três altares nas capelas de São Miguel, São Bartolomeu e Santa Quitéria"24.

Hoje, as três capelas laterais do lado da epístola encontram-se razoavelmente bem conservadas, enquanto as três capelas do lado do evangelho não possuem mais os retábulos em madeira e, sim, cópias em argamassa. Apesar disso, observando com cuidado, ainda podemos encontrar alguns vestígios dos altares originais, como emblemas e restos de pinturas.

Sendo assim, existe na mesa do altar da primeira ${ }^{25}$ capela lateral do lado da epístola o monograma "SM", que poderia indicar a Capela de São Miguel citada no Catálogo. (fig. 03 e 04)

16 COSTA, Lúcio. A arquitetura dos jesuítas no Brasil (1941). In: Revista do Patrimônio. 6 o anos: a Revista. Rio de Janeiro: Iphan, $1997, \mathrm{n}^{\circ} 26$.

17 Idem, ibidem, p. 113 .

18 O Colégio do Embu tem pátio modesto e o de Paranaguá, um aspecto sombrio de "praça-forte". Ver: COSTA, op. cit., 1997, p. 115.

19 MANUSCRITO DO CATÁlOGO. op. cit., p. oı.

20 Ibidem, p. or.

21 Ibidem, p. o1.

22 Ibidem, p. or.

23 Ibidem, p. o1.

24. Ibidem, p. o1.

25 Primeira capela do lado da epístola (lado direito) para quem ingressa na igreja. 
Quanto aos retábulos das capelas do lado da epístola (fig. 05), podemos observar que os três possuem colunas de formas torças, decoradas com folhas de parreira e aves fênix ${ }^{26}$, como a maior parte dos retábulos entalhados em Portugal entre 1675 e $1725^{27}$.

Porém, estas colunas estão colocadas numa nova disposição $0^{28}$ (como o altar-mor da igreja), isto é, separadas por um nicho destinado à exposição de imagem esculpida, o que poderia indicar a utilização ou reaproveitamento de peças oriundas de retábulos anteriores. Desta forma, os retábulos seriam resultados das montagens de peças de retábulos de modelos "antigos" e "modernos" (fig. 06).

Os outros monogramas ("SJ", "SA", "SS", "DB") das mesas dos altares das capelas laterais não parecem aludir às invocações citadas no Catálogo (São Bartolomeu e Santa Quitéria). Enfatizamos, no entanto, que existe uma mesa de altar que não possui mais o monograma ( 2 a capela do lado do evangelho) e que as iniciais "DB" podem, na verdade, ter sido "SB", de São Bartolomeu.

O Catálogo também faz menção a duas pias: "Tem mais duas pias de água benta, obra de embutido preciosa." ${ }^{29}$ Estas duas belíssimas pias são de pedra lavrada (lioz) e estão ainda hoje no batistério da igreja.

Acerca da fachada da Igreja de São Francisco Xavier (fig. 07), o $\mathrm{Ca}$ tálogo nos diz: "No frontispício, que acompanham duas torres, por remate uma formosa cruz de jaspe ${ }^{30}$; sobre a cornija mestra três nichos, de Nossos Santos Padres Inácio, Xavier e Borja - dois andares de janelas rasgadas com suas grades de correspondência das portas. Nas torres estão sinos; não ainda acabadas, posto que já tem cal, pedra, tijolo, oficiais para se fazerem." ${ }^{31}$

Como fica claro na imagem (fig. 07), a fachada obedece à mesma disposição apresentada no Catálogo (três corpos horizontais e cinco verticais, duas torres e cornija mestra), não possuindo mais as imagens de Santo Inácio, São Francisco Xavier e São Francisco de Borja nos três nichos.

Retornando ao espaço interno da Igreja de São Francisco de Xavier, em relação à sacristia, o Catálogo nos diz:

26 O que Robert Smith chamou de "estilo nacional português". Sobre o estilo nacional, ver SMITH, Robert. A talha em Portugal. Lisboa: Livros Horizonte, 1962, p. 69-74.

27 Idem, ibidem, p. 72.

28 O que Robert Smith chamou de "estilo joanino". Sobre o estilo joanino, ver SMITH, Robert. op. cit., p. 95-100.

29 MANUSCRITO DO CATÁLOGO. op. cit., p. ol.

zo Jaspe: Variedade de calcedônia muito usada como pedra ornamental devido às múltiplas cores que apresenta, resultantes de inclusões de óxido de ferro; jasperita. Ver HOUAISS, Antônio; VILLAR, Mauro. Dicionário Houaiss da língua portuguesa. Rio de Janeiro: Objetiva, 2oo1, p. 1.677.

31 MANUSCRITO DO CATÁLOGO. op. cit., p. o1-o2. 
Fica esta na ilharga da capela-mór parte do poente, a fim de ficarem os ornamentos mais guardados das umidades, dos tempos e roubos: tem o mesmo comprimento da Capela-mór e largura do braço do Cruzeiro. Pela parte do corredor do Colégio tem uma porta no meio, e nas ilhargas 2 - armários, por modo de escritórios para amictos, missais, cálices e outras miudezas necessárias a seu serviço, com molduras de jacarandá e pau amarelo, por modo de xadrez. Tem outra porta fronteira a esta para serventia do Cruzeiro e capelas. Tem mais junto da pilastra do arco grande uma porta para a Capela-mór e fronteira a esta outra parte do pátio outra que vai para o púlpito, em que se entra por dentro da parede que fica sobre os arcos interiores das capelas, para que se sobe por suas escadas cobertas que ficam no pátio. Tem esta Sacristia, 2 janelas grandes para o pátio e outra pequena, no meio, sobre o lavatório, ficando de fronte os caixões dos ornamentos com muita claridade. As paredes estão ornadas com formosos painéis do Batismo de Cristo e vida da Senhora. Tem sobre o caixão do meio um crucifixo de metal, com uma lâmina de Santa Maria Madalena. Tem dossel com espaldar de chamalote verde e carmesim. ${ }^{32}$

Ainda estão presentes no espaço da sacristia, as duas janelas para o pátio, sendo que os dois armários, a janela menor, o lavatório e as paredes ornadas com painéis do batismo de Cristo e da vida de Nossa Senhora não mais existem. O Catálogo não menciona a pintura de forro, portanto, é possível que a mesma tenha sido executada após 1720.

Na sequência sobre a sacristia, capítulo segundo, o Catálogo nos fala sobre um crucifixo de metal e uma pintura sobre metal ("lâmina") 35 de Santa Maria Madalena, colocados acima do arcaz ("caixão") ${ }^{34}$. Pelo que observamos, estas obras não mais se conservam na igreja. Tomamos conhecimento, através do Museu de Arte Sacra do Pará, que o crucifixo que hoje encontramos no retábulo pertencia a outra igreja e foi datado do século XIX.

O Catálogo também cita duas imagens de Santa Quitéria que ficariam na sacristia. Encontramos na reserva técnica do Museu de Arte Sacra do Pará (desde 1998, a igreja e o Colégio de Santo Alexandre funcionam como museu) uma imagem de Santa Quitéria ${ }^{35}$ com características do século XVIII e que poderia ser uma das quais o Catálogo faz referência.

32

33

34

35

Ibidem, p. 02.

Ibidem, p. 02.

Ibidem, p. 02.

Santa Quitéria: Uma das santas mártires. Viveu em época incerta. Conta sua lenda que foi filha de um nobre galego e pagão. Fez-se batizar às escondidas e, por conta disto, foi decapitada tempos mais tarde. É representada como donzela ou princesa ro- 
Ao final do capítulo 2o "Da sacristia e do que lhe pertence", faz-se menção aos altares: “... para os altares em 1718 comprei dois tapetes, mandei fazer ramalhetes de papel; seda; e penas que servem nos altares e jarras de Veneza para os ditos ramalhetes" ${ }^{36}$. Esta passagem pode nos indicar que os altares da sacristia ficaram prontos em 1718 e que os ornamentos e flores foram adquiridos em comemoração deste feito. Seguindo com esta hipótese, poderíamos pensar que as compras foram feitas para a inauguração da Igreja de São Francisco Xavier, fixando a data em 1718 e afastando a dúvida que paira entre os anos de 1718 e 1719.

O capítulo 3o do Catálogo trata "Da capela da comunidade dedicada ao São Borja", a qual localizava-se no piso superior, exatamente acima da sacristia, "com o mesmo espaço dela" "37. O texto do documento cita um retábulo de São Francisco de Borja, um sacrário e duas tribunas para a capela-mor, todos não mais existentes, como pudemos verificar.

Quanto às imagens escultóricas, são mencionadas, além da imagem de São Francisco de Borja, duas imagens pequenas de Nossa Senhora e São Francisco Xavier, um crucifixo pequeno em "uma cruz coberta de tartaruga e engastes de prata." ${ }^{38}$ Existem, na igreja, uma imagem de São Francisco de Borja ${ }^{39}$ e uma de São Francisco Xavier, datadas do século XVIII, mas não podemos afirmar que seriam aquelas pertencentes à capela doméstica.

O capítulo 4o do Catálogo trata da livraria, onde teria existido um "nicho com guarnição de talha e nele uma perfeita imagem de Nossa Senhora com o menino nos braços, e este dito aos pés, Sedes Sapientiae" ${ }^{\text {. }}$. Hoje não se encontram preservados, nem o nicho, nem a imagem da Senhora. A livraria naquele ano possuía 1.263 volumes.

No capítulo 7o, “Dos escultores, pedreiros e carpinteiros”, extraímos, como já citamos na introdução deste trabalho, o ano em que o $\mathrm{Ca}$ tálogo foi escrito, $1720^{41}$. Além disso, neste capítulo descobrimos que o

mana, com a túnica e o pálio. Seu atributo pode ser um diabo na forma humana, ou um cachorro. É mais comum uma espada ou ainda um corte no pescoço (todos ausentes nesta peça) Ver Acervo do Museu de Arte Sacra do Pará, p. 03 (não publicado).

MANUSCRITO DO CATÁLOGO. op. cit., p. oz.

Ibidem, p. oz.

38 Ibidem, p. oz.

39 São Francisco de Borja: Terceiro geral dos jesuítas. Nascido em Valência em 1510, morreu em Roma em 1572. Teve vida leiga até entrar para a Companhia de Jesus em 1546. Fundou um novo noviciado em Roma, multiplicou as missões e reorganizou os métodos de ensino. Foi beatificado em 1624, e canonizado em 1671. Seu atributo é uma caveira coroada, alusão à visão dos despojos mortais da imperatriz Isabel de Portugal, mulher do imperador Carlos V, razão que motivou sua renúncia à vida mundana. Ver Acervo do Museu de Arte Sacra do Pará, p. 6 (não publicado). 
Colégio possuía duas oficinas onde estes oficiais trabalhavam, utilizando instrumentos como compassos, enxadas, martelos, plainas, entre ou$\operatorname{tros}^{42}$. Aos pedreiros pertencia uma outra gama de ferramentas: pincéis, prumos, marretas, picaretas etc. ${ }^{43}$

Também quanto aos escultores, através do Catálogo (capítulo 9oa), sabemos que:

Se fizeram a primis fundamentis ${ }^{44}$ no pedaço do corredor novo pelas costas da capela-mor em que ficam duas janelas rasgadas, uma para baixo com grades, uma para cima com gelosias, dois cubículos, um para a Botica, e serve entretanto ao Irmão Escultor e rapazes que aprendem ... ${ }^{45}$

No ano de 1720, trabalhava no Colégio o jesuíta tirolês João Xavier Traer (1668-1737), escultor e pintor, proveniente do Colégio de Viena, que viveu no Estado do Maranhão e Grão-Pará entre os anos de 1703 e $1737^{46}$, e que provavelmente deveria ser o "Irmão Escultor" que ensinava o ofício aos "rapazes" índios ou negros, como veremos em seguida.

Poderíamos pensar, portanto, que Traer seria o autor de várias imagens esculpidas e dos retábulos produzidos naquele período para a Igreja e o Colégio. Apesar da origem não ibérica do mestre escultor, os retábulos das capelas laterais e da capela-mor da Igreja de São Francisco Xavier, como vimos, são tipicamente portugueses.

Sendo assim, cria-se a hipótese de que apesar dos padres artistas trazerem de seus países de origem as bases para o desenvolvimento de suas atividades artísticas nas colônias, nem sempre as aplicaram, pois a influência da Coroa, no caso Portugal, sempre prevaleceu nas obras de maior porte como altares e retábulos.

Também podemos verificar a ocorrência do mesmo fato no século XVII, no trabalho artístico do padre João Felipe Bettendorff ${ }^{47}$, luxemburguês, que desenha o retábulo da Catedral de São Luís do Maranhão, também oriundo do repertório português.

Quanto ao púlpito, o mesmo é citado, mas curiosamente não descrito pelo redator do Catálogo. A ausência da descrição de uma peça tão significativa e, de certa maneira, até "extravagante" pela sua composi-

42 Ibidem, p. oz.

43 Ibidem, p. 05.

44 Expressão latina que significa "desde os alicerces".

45 MANUSCRITO DO CATÁLOGO. op. cit., p. oz.

46 LEITE, Serafim. Artes e ofícios dos jesuitas no Brasil. op. cit., p. 272.

47 Ver BETTENDORFF, João Felipe. Crônica da missão dos padres da Companhia de Jesus no Estado do Maranhão. Belém: Secult, 1990. 
ção que, por exemplo, não passou despercebida a Lúcio Costa ${ }^{48}$, deixanos em dúvida sobre a existência do púlpito na sua forma atual naquele período: "Tem mais junto da pilastra do arco grande uma porta para a Capela-Mor e fronteira a esta outra parte do pátio outra que vai para o púlpito, em que se entra por dentro da parede que fica sobre os arcos interiores das capelas, para que se sobe por suas escadas cobertas que ficam no pátio."49

Vale observar também que o autor do Catálogo menciona apenas "o púlpito" e não o par de púlpitos. Por outro lado, no Inventário de $1760^{50}$, são assim mencionados: "tem mais a Igreja dois púlpitos de fábrica moderna de madeira entalhada, e esculpida tudo dourado, e de extremosa beleza."51

Talvez, nestes púlpitos (fig. 08) de características tão singulares, Traer pôde utilizar com maior liberdade o repertório trazido da Áustria, ou melhor, do barroco da Europa Central. Estas questões fundamentais, ligadas ao padre João Xavier Traer ${ }^{52}$, ao repertório austríaco e português, pretendemos investigar com maior atenção em nossa tese.

Vimos que no Colégio havia duas oficinas, ratificadas pela presença do “irmão escultor e rapazes que aprenderem." ${ }^{" 53}$ Quem seriam, portanto, os artistas e oficiais não jesuítas que trabalhariam no Colégio? O capítulo 10 "Dos oficiais que tem o Colégio" é esclarecedor neste sentido. Daí a importância deste Catálogo, como um documento privativo do Colégio, como nos alertou Leite ${ }^{54}$, pois, aqueles que eram enviados a Roma não continham este tipo de informação, pois descreviam basicamente a atividade dos padres da Companhia nos colégios das missões.

48 "Na composição e na talha de uns e de outros [os numerosos altares e principalmente os púlpitos de Santo Alexandre], observa-se o mesmo acento bárbaro referido anteriormente, quando aludimos à arquitetura dessa igreja. Mas, apesar da técnica grosseira, de que resultou, por vezes, um aspecto quase grotesco, apesar da falta de escala e de meia-tinta, o arrojo plástico e o sentido apaixonado da concepção dos púlpitos revelam um tal fervor, tamanho arrebatamento, que a sua análise não cabe dentro dos limites comedidos de uma crítica objetiva. A impetuosidade com que as formas irrompem pela parede acima tem mesmo qualquer coisa de telúrico, fazendo lembrar esculturas hindus talhadas sobre encosta de montanha.” COSTA, Lúcio. op. cit., p. 138.

MANUSCRITO DO CATÁLOGO. op. cit., p. oz.

FONDO BRASILIAE 28 , ARSI.

Ibidem, f. 9 r. ção e bibliografia acerca do trabalho de jesuítas não ibéricos nas missões da América, além de documentação primária sobre João Xavier Traer (cartas, autógrafos, catálogos, Indipetae, Elogiae).

54. LEITE, Serafim. Artes e ofícios dos jesuitas no Brasil. op. cit., p. 23-26. 
Este belo capítulo, não publicado em Lamego ${ }^{55}$, será transcrito e publicado por Serafim Leite em Artes e oficios ${ }^{56}$, dada a relevância para 0 tema. A nossa transcrição traz pequenas diferenças, como por exemplo, quanto aos nomes dos escultores índios de Gibirié ${ }^{57}$, citados por tantas vezes em trabalhos de outros estudiosos que consultaram Leite ${ }^{58}$, e que lemos Marçal (e não Manuel), Ângelo e Faustino:

Tem pedreiros Francisco Massus, preto e Manuel Garcia, preto, escravos pertencentes a Jaguarari como os quais, Estevão da dita fazenda apreenderam nestes anos Manuel preto, e Mathias Índio da Fazenda de Gibirié, Cayetano Índio forro da fazenda de Mamayacu. Ferreiros ensinados nestes anos Cazimiro e Sylvestre índios, Pero preto, e Lázaro seu filho forro pela [mais] da fazenda de Gibirié. Miguel preto e Ignácio escravos da fazenda de Jaguarari ${ }^{59}$. Carpinteiros Ignácio e Feliz pretos escravos da fazenda de Jaguarari. Antônio Guaiapi e Raymundo Tupinambá e Mandu Gregório da Fazenda de Mamayacú ${ }^{60}$. Severino e João Índios deixados ao Colégio. Mandú cafuzo, escravo do engenho de Ibyrajuba. Escultores Marçal, Ângelo, e Faustino Índios de Gibirié, escravos. Torneiros Antônio, Clemente, Índios escravos, de Gibirié. Alfaiates: Francisco preto e Duarte Índio, e Antônio Corcovado pretos escravos da fazenda de Jaguarari. Tecelões de novo apreenderam Januário de Gibirié e Antônio forro em Mamayacú. Além destes oficiais, que de ordinário assistem no Colégio têm as Fazendas outros para seu serviço que nos Catálogos se faz menção, e principalmente têm canoeiros e serradores. ${ }^{61}$

Vemos, por conseguinte, uma mistura de raças: são índios, cafuzos, negros, em grande parte escravos, trabalhando como oficiais nas obras do Colégio do Pará. Vale ressaltar que, na mesma relação de ofi-

55 LAMEgo, Alberto Frederico de Morais. A Terra Goytacá a luz de documentos inéditos, 4, v. Paris: L'Édition d'Art, 1913.

56 LEITE, Serafim. Artes e ofícios dos jesuitas no Brasil. op. cit., p. 25-26.

57 Gibirié: Antiga aldeia e fazenda dos jesuítas no interior do Pará, hoje chamada Barcarena Velha.

58 Como por exemplo em BÓGEA, Kátia; BRITO, Stella; RIBEIRO, Emanuela. Olhos da alma: escola maranhense de imaginária. São Luís: s/e, 2002, p. 55; em OLIVEIRA, Myriam; BRAZÓN, Mariela. La epopeya jesuitica em el Amazonas brasilero y sus imágenes. Sevilha: III Congresso Internacional do Barroco Ibero-Americano, 2001, p. 529 .

59 Jaguarari: Antiga fazenda jesuítica às margens do rio Mojú no Pará. Hoje apenas existem ruínas da antiga igreja.

6o Mamayacú ou Mamaiacú: Antiga fazenda dos jesuítas no interior do Pará, hoje chamada Porto Salvo.

61 MANUSCRITO DO CATÁLOGO. op. cit., p. o6. 
ciais, estão tanto os escultores, quanto os tecelões, carpinteiros e pedreiros. Os oficiais vêm principalmente das fazendas de Gibirié, Mamaiacú, Ibirajuba e Jaguarari, localidades relativamente próximas a Belém e que também forneciam, como Mamaiacú desde o século XVII ${ }^{62}$, materiais (grades, telhas) para as obras do Colégio de Santo Alexandre e que, provavelmente por este motivo, deveriam ter oficiais mais qualificados.

O capítulo 11o trata das despesas e receitas do Colégio de Santo Alexandre e os capítulos 12 e 13o das dívidas do Colégio a "pessoas de fora" ${ }^{63}$, e do que devem ao Colégio, não sendo encontrados trechos significativos para o nosso tema.

\section{O texto do Catálogo ${ }^{64}$}

Catálogo deste Colégio de Santo Alexandre, seus bens, oficinas, fazendas, servos, gados, dispêndios, e dividas ativas e passivas

\section{Capítulo 1o Dos bens deste Colégio}

[p. 01] É este Colégio formado em figura quadrada, sito na melhor parte da cidade e sobre a Praça e mar. Que também é a fortaleza de uma formosa Igreja em que as bandeiras despregadas, contra os vícios mostram seus filhos o valor de Jesuítas, pregando, confessando e dizendo Missa de madrugada nos dias Santos, com notável concurso do povo, que por sua pobreza, embrulhados no escuro da noite a vem ouvir. Tem esta Igreja de comprido, das grades do cruzeiro até as portas principais do Frontispício 192 palmos $^{65}$, de largo 58, de alto tem os mesmos. Das grades do dito Cruzeiro até as da Comunhão, 30. A capela-mór da dita Igreja tem do arco para dentro 50 palmos de alto, e 5 degraus para o altar-mor em cujas ilhargas ${ }^{66}$ ficam 2 cardencias $^{67}$.

62 BETTENDORFF, João Felipe. op. cit., p. 548.

63 MANUSCRITO DO CATÁLOGO. op. cit., p. o7.

64. Como citado anteriormente, a transcrição foi realizada em conjunto com o nosso orientador, Prof. Dr. Luciano Migliaccio, no ano de 2007.

65 Palmo: Medida de comprimento equivalente a vinte e dois centímetros, ou seja, o palmo da mão aberta. Ver ÁVILA, Affonso. Barroco mineiro: glossário de arquitetura e Ornamentação. Belo Horizonte: Fundação João Pinheiro, 1980. p. 212.

66 Ilhargas: Peças frontais de esteio de um retábulo, arco-cruzeiro etc. que aparecem lateralmente em relação ao vão central. Equivaleriam à ombreira dos outros vãos. Ver ÁVILA, Affonso. op. cit., p. 151.

67 Credencias: Não encontramos verbete no dicionário português, provavelmente palavra oriunda do italiano credenzia, ou seja, nicho, vão. Plural (it.): credenze. 
Ficam nesta Capela 4 tribunas $^{68}$, e 2 Nichos cada um de sua parte, o arco maior tem 33 palmos de vão, de alto pela volta de baixo 53, a cabeça 2, a cornija mestra que corre e cinge toda a Igreja 3. Tem esta Igreja Cruzeiro e Capelas fundas: o Cruzeiro tem do arco maior até o degrau do braço que mete na pilastra 30, e de fundo 20, e seu arco tem 35, 20 de pé direito; e 15 de volta. Tem as capelas por cima suas tribunas em 12 palmos de vão, e 8 de alto sobre as quais corre uma cornija de 2 palmos, antes da cornija mestra que com seu colarete corre em 3 palmos de alto, e 2 de sacada. Tem mais a dita Igreja de mais 3 altares nas capelas de São Miguel, São Bartolomeu, Santa Quitéria, fechadas com grades e seus confessionários. Tem mais 2 pias de água benta, obra de embutido preciosa. No frontispício, que acompanham 2 torres, por remate uma formosa cruz de jaspe; sobre a cornija mestra 3 nichos, de Nossos Santos Padres Inácio, Xavier, e Borja - dois andares de janelas rasgadas com suas grades em correspondência das portas. Nas torres estão sinos; não ainda [p. 02] acabadas, posto que já tem cal, pedra, tijolo, oficiais para se fazerem. Tem mais esta Igreja sua capela-mór, uma Sacristia e uma formosa casa de despejos, e serventia para camarim toda grave, clara e com boa serventia.

\section{Capítulo 2ํㅗ Da sacristia e do que lhe pertence}

Fica esta na ilharga da capela-mór parte do poente, a fim de ficarem os ornamentos mais guardados das umidades, dos tempos e roubos: tem o mesmo comprimento da Capela-mór e largura do braço do Cruzeiro. Pela parte do corredor do Colégio tem uma porta no meio, e nas ilhargas 2 - armários, por modo de escritórios para amictos ${ }^{69}$, missais, cálices e outras miudezas necessárias a seu serviço, com molduras de jacarandá e pau amarelo, por modo de xadrez. Tem outra porta fronteira a esta para serventia do Cruzeiro e capelas. Tem mais junto da pilastra do arco grande uma porta para a Capela-mór e fronteira a esta outra parte do pátio outra que vai para o púlpito, em que se entra por dentro da parede que fica sobre os arcos interiores das capelas, para que se sobe por suas escadas cobertas que ficam no pátio. Tem esta Sacristia, 2 janelas grandes para o pátio e outra pequena, no meio, sobre o lavatório, ficando de fronte os caixões dos ornamentos com muita claridade. As paredes estão ornadas com for-

68 Tribuna: Lugar reservado e elevado, com abertura em janelas ou varandas, para assistir às cerimônias religiosas. Ver ÁVILA, Affonso. op. cit., p. 90.

69 Amicto: Pequeno pano branco com que o sacerdote cobre o pescoço e os ombros, por baixo da alva, ao paramentar-se para a missa. Ver HOUAISS, Antônio; VILLAR, Mauro. op. cit., p. 188. 
mosos painéis do Batismo de Cristo e vida da Senhora. Tem sobre o caixão do meio um crucifixo de metal, com uma lâmina de Santa Maria Madalena. Tem dossel com espaldar ${ }^{70}$ de chamalote ${ }^{71}$ verde e carmesim $^{72}$. Tem a Igreja cortinas e sanefas ${ }^{73}$ de chamalote, e brocadel $^{74}$, para as portas e tribunas guarnecidas de prata e ouro, como também os nichos dos Apóstolos São Pedro e São Paulo. Uma colcha de damasco carmezim, guarnecida de damasco verde com franja de ouro, para as costas do sacrário, no campo debaixo da tribuna. Um pavilhão pequeno de chamalote para expor o Santíssimo nas renovacões e Novena, 5 alvas de festa, amictos, corporaes $^{75}$, guardas ${ }^{76}$, sangüíneos ${ }^{77}$ tudo de novo e mais que pertence aos ornamentos velhos, de que se faz expressa menção no Inventário de entrega. Todas as tribunas e portas têm seus varões de ferro estáveis para as cortinas; todas as portas, grades e confessionários e 2 Imagens de Santa Quitéria, que se fizeram de novo; para os altares em 1718 comprei 2 tapetes, mandei fazer ramalhetes de papel, seda; e penas que servem nos altares e jarras de Veneza para os ditos ramalhetes.

\section{Capitulo 3o Da capela da comunidade dedicada ao São Borja}

Fica esta sobre a Sacristia, com o mesmo espaço dela. É forrada de volta de cordel, e tem seu retábulo, tem duas [p. 03] tribunas para a Capela-mór, 3 janelas para o pátio. Na parede do frontispício, que é também do Colégio, fica a porta principal, para a qual se sobe do corredor, 11 degraus, em respeito de ficar a Sacristia desafogada, faz

70 Espaldeira: Pano para cobrir o espaldar de uma cadeira ou os varais de um dossel. Ver HOUAISS, Antônio; VILLAR, Mauro. op. cit, p. 1.222.

71 Chamalote: Fazenda de textura similar à do tafetá, cuja trama produz efeitos ondulados no lado direito do tecido. Tecido grosso originado do Oriente feito com pêlos de camelo; e por vezes, de cavalo. Ver HOUAISS, Antônio; VILLAR, Mauro. op. cit., p. 687.

72 Carmesim: A cor vermelha do carmim. Ver HOUAISS, Antônio; VILLAR, Mauro. op. cit., p. 628 .

73 Sanefa: Larga tira de tecido que se coloca na parte superior da cortina ou reposteiro, nas vergas da janela etc., geralmente rematada com franja ou galão. Ver HOUAISS, Antônio; VILLAR, Mauro. op. cit., p. 2509.

74. Brocado: Diz-se de ou tecido de seda com largos relevos bordados a ouro e/ou prata. Ver HOUAISS, Antônio; VILLAR, Mauro. op. cit., p. $5^{\mathbf{1} 6 .}$

75 Corporal: Tecido quadrangular de linho branco que o sacerdote estende sobre o altar e no qual pousa o cálice e a hóstia durante a missa; pano sagrado. Ver HOUAISS, Antônio; VILLAR, Mauro. op. cit., p. 844.

76 Guarda: Guarda do frontal. Pano de seda, liso ou bordado, que pende no meio do frontal. Ver HOUAISS, Antônio; VILLAR, Mauro. op. cit., p. 1.492.

77 Sangüíneo: Sanguinho. Pequeno pano com que o sacerdote enxuga o cálice, depois de comungar; sangüíneo, purificador. Ver HOUAISS, Antônio; VILLAR, Mauro. op. cit., p. $2.5^{10}$. 
a dita escada, 2 braços para uma outra parte do corredor, ficando a parte de que a respeita coberta de uma linda talha. Fronteiro à porta fica o retábulo, o altar digo do glorioso São Borja em que está sua formosa Imagem, um Sacrário de mais anos, 2 imagens pequenas de Nossa Senhora e São Xavier também de mais anos, um crucifixo pequeno em uma cruz coberta de tartaruga e engastes de prata, pertence a este altar um frontal de semana, um ornamento rico de festa, com todo o necessário. Uma armação inteira de brocadel verde e carmezím, cortinas, e sanefa do mesmo para a porta. Uma cadeira de talha para as práticas, arquibancos para a comunidade em roda; nas ilhargas da porta estão 2 armários com gavetas pequenas por cima para os amictos, e grandes por baixo para os ornamentos a modo de mesa, para se revestir o sacerdote. Tem nas costas do altar uma casinha, com uma caixa grande, para conservar tudo o que lhe pertence. Tem um tapete de algodão, uma lâmpada de prata; ficalhe no corredor uma ante-sala, ornada com alguns painéis antigos, mas em bom uso, renovados nas pinturas, e molduras.

\section{Capítulo 4o Da livraria}

Fica esta no corredor, que respeita ao poente, feita de 2 cubículos, abriu-se-lhe para a parte do retrete ${ }^{78}$. Uma porta com seu frontispício, e um Jesus ${ }^{79}$, obra de talha: para a mesma parte do poente se abriram 3 janelas, uma rasgada no meio, e duas mais pequenas nas ilhargas. Fronteiro a porta fica um lindo nicho, com sua guarnição de talha, e nele uma perfeita imagem de Nossa Senhora com o menino nos braços, e este dito aos pés, Sedes Sapientiae. Tem a dita imagem sua coroa de prata, e o nicho suas cortinas de chamalote verde, guarnecidas de galão de prata, acrescentaramse as estantes, e se lhe fizeram caixilhos, por modo de xadrez. Tem as estantes uns remates em tarjas de talha para os dizeres das matérias. Meteram-se nestes anos, cinco volumes com 1.258 que tinha fazem 1.263. Compraram-se mais de cem volumes ao Doutor Ouvidor Geral por 600 cruzados, que ficam pagos.

Capítulo 5o Da rouparia e botica que se acham juntas, por falta de lugar Tem conforme o seu inventário - 2 caixas grandes, e uma pequena, um Baú, 2 escritórios, 2 salvas de prata, uma grande, outra peque-

78 Retrete: Aposento mais recôndito de uma habitação, destinado ao descanso, ao retiro. Ver HOUAISS, Antônio; VILLAR, Mauro. op. cit., p. 2448.

Provavelmente, o nome de Jesus grafado. 
na, um púcaro grande de conchas, 12 colheres, 11 garfos e um copo tudo também de prata, 3 bacias grandes de lavar os pés e sangrias, 2 pequenas. Um almofariz, 2 lambiques, 2 [gracos] de pregos [p. 04] de cadeiras, 3 candeias de azeite, peças de estanho sorteadas - 64, de vidro - 14. Roupa de toalhas e guardanapos. Um terno de algodão, dois ferros do refeitório. Toalhas de linho, e do lavatório - 6, de algodão - 6, de mãos, e lava pés - 8, Louça fina, peças sorteadas 16, Pano para [Barretes] e vestes. [Facaria] [para] tem mais todas as miudezas necessárias, com todo provimento deste ano. Botica: Tem esta suas estantes antigas, com vidros, vasos, bocetos, e balança; alguns medicamentos antigos e não deste ano.

\section{Capítulo 6o Da despensa, refeitório, cozinha}

Tem a despensa um caixão antigo que serve de Paiol, um armário, uma guarda de cobre nova. Uma frasca de nove frascos, mais duas com 160 frascos para conservar o vinho, um funil de cobre. Manteigas e azeites da terra em abundância. Pertence-lhe uma barrica de vinho com as quatro deste ano, 2 barris de azeite, 3 [grais] de ferro e bronze, outro de pedra, e um almofariz pequeno, 2 [grais] de cobre, 3 bacias pequenas, velhas, o que tudo pertence à Botica.

\section{Refeitório}

12 [?], 6 [almafias], 10 [sal?], 11 pratos de porção, 4 [almafias] pequenas, 12 [sal?] pequenas, 22 tigelas, 20 caixas de galhetas, 14 facas, 16 colheres, 15 garfos, 12 saleiros, copos grandes, e pequenos jarros.

Cozinha

Tem de cobre caldeirões 4, [Tachos] 5, e um de arame, frigideiras 2 , colheres 3, escumadeiras 1, almofa[?] 1, mais de novo 7 colheres de ferro, o machado cutelos.

\section{Capítulo 7o Dos escultores, pedreiros e carpinteiros}

A 1- oficina conforme seu inventario pertencem: Machados 4, enxós 4, [b?] 3, serras 4, ferros de cova 2, formões 46, goivas 81, compassos 1, enxadas 2, grilhões 3, algemas 2, ferros de aplainar 4 ferros de junta 2 , fechaduras 2 , martelos 8 , veios para fazer cordas 3, Deste ano de $1720^{80}$ e comprei mais 167 peças de toda casta para os ditos ofícios.

Tem a 2 a oficina, machados 18 , toucas 7 , serras braçais 3 , serras de mão 2, serrotes 3, enxós de carapina 10, ferros de Canoa 2. Uma 
enxó de Canoa, ferros de cova 6, juntas 4, plainas 1, cantis 3, copos de [ornadelos], machos 7 , fêmeas 5 , barriletes 2 , braças 2 , [vemas] grandes 12 , pequenas 8 , [guilhemes] 5, formões grandes 4 , pequenos 5, Ferros de tornear, compassos 2, enxadas grandes e pequenas 8, machados de cravo 20, [onacelos], alavancas 1, ponteiros 4, escopos 2, calafetas 3, goivas 2, esporas 2, badarmes 2, tem mais ferramentas [p. 05] pertencentes a canoas, Machados 19, verrumos 4, facões 4, enxós 1.

\section{Pedreiros}

A estes pertencem [camardelos] 8, colheres grandes 7, pincéis 8, prumos 2, 1 marrão, 1 marreta, 4 picaretas, 1 colher. Tem mais varias ferramentas que se compraram este ano devido, e mais 30 pederneiras para as armas de fogo dos currais 130.000 cruzados.

Capítulo 8 o Dos muros da cerca que de novo se fizeram de pedra e cal Fizeram-se estes de novo e principiam da esquina da torre com consentimento da Câmara e carta para meter dentro deles um pedaço de terra em que ficam pátios ou quintais pequenos para flores despejos da Sacristia, e algumas árvores preciosas que já tem: Nestes muros se fez uma casa por modo de torre com seu frontispício, com um meio corpo de grades que serve para os Passos Públicos da Cidade, e tem um bem pintado painel da Coroação de Nossa Senhora.

Capítulo 9o De um cubículo debaixo da livraria para guardar o que pertence aos padres que vão para as missões e fazendas

Tem uma frasqueira da terra com 8 frascos comprados por 20 cruzados, mais 2 de 15 frascos cada uma, casco também, e ferragem feitas na terra por 6 cruzados, mais esta frasqueira de 12 frascos pequenos por 12.000, mais outra sem frascos. Herdadas pelo Colégio do Padre Miguel Coelho Pinto sem ferragem com valor de 60 cruzados, mais uma frasqueira de 6 frascos, Casco do Reino 9, mais outra de 6 frascos pequenos casco rodo, e pobre por 7 . Uma caldeira de cobre para comerem 160, 3 velas de canoa com 11, 26 \$ 800. Uma escopeta $5 \$$ 400 , mais 2 somemos $30 \$ 000$, mais 2 para as canoas de viagem 24 \$ 000. Um terçado $5 \$ 400$, uma pistola e um pedaço de espingarda velha 800, 2 espingardas de Braga 50 \$ 000, o que tudo é necessário para as viagens, gente bruta, bichos peçonhentos, tigres, etc. e passa o valor de 2.800 \$. Em lugar deste cubículo ocupado, com o acima, e mais alguma louça necessária, ferramentas, arcos e flechas para 
os currais. Se fizeram a primis fundamentis no pedaço do corredor novo pelas costas da Capela-mór em que ficam duas janelas rasgadas, uma para baixo com grades, uma para cima com gelosias, dois cubículos, um para a Botica, e serve entretanto ao Irmão Escultor e rapazes que aprendem, e por cima da mesma sorte 2 cubículos, um para o Padre Superior, servindo um para a cama e livraria, e oratório, outra sala para as consultas com uma [p. 06] janela rasgada para 0 nascente com sua gelosia e 2 ordinárias para o Norte entre as quais fica um nicho com um crucifixo e suas cortinas de seda fronteiro a porta principal e também a porta que passa para o outro cubículo sem suas cortinas.

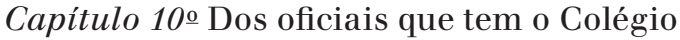

Tem pedreiros Francisco Massus, preto e Manuel Garcia, preto, escravos pertencentes a Jaguarari como os quais, Estevão da dita fazenda apreenderam nestes anos Manuel preto, e Mathias Índio da Fazenda de Gibirié, Cayetano Índio forro da fazenda de Mamayacu. Ferreiros ensinados nestes anos Cazimiro e Sylvestre índios, Pero preto, e Lázaro seu filho forro pela [mais] da fazenda de Gibirié. Miguel preto e Ignácio escravos da fazenda de Jaguarari. Carpinteiros Ignácio e Feliz pretos escravos da fazenda de Jaguarari. Antônio Guaiapi e Raymundo Tupinambá e Mandu Gregório da Fazenda de Mamayacú. Severino e João Índios deixados ao Colégio. Mandú, cafuzo, escravo do engenho de Ibyrajuba. Escultores Marçal, Ângelo, e Faustino, Índios de Gibirié, escravos. Torneiros, Antônio, Clemente, Índios escravos, de Gibirié. Alfaiates: Francisco preto e Duarte Índio, e Antônio Corcovado pretos escravos da fazenda de Jaguarari. Tecelões de novo apreenderam Januário de Gibirié e Antônio forro em Mamayacú. Além destes oficiais, que de ordinário assistem no Colégio têm as Fazendas outros para seu serviço que nos Catálogos se faz menção, e principalmente têm canoeiros e serradores.

Capítulo 11ํㅡㄹ Das despesas e receitas deste Colégio com várias [?] desde 1715 até 1720 do que consta das contas para [?] deve particulares como se vê no dito foglio 105

Deve com se vê no dito fl. 105 - 1370,20 cruzados.

(Hade Haver) fl. 115 - 1012,518 cruzados.

Das contas do mesmo em receita fl. 82. - 2.015, 200 cruzados.

Das contas do mesmo em despesa fl. 98. - 6.057,445 cruzados. 
Com advertência de estar satisfeito Excesso com o que venderam as fazendas ut bene notatur fl. 97 e 98.

Das contas do Colégio com a Procuradoria das Missões de [?], seus provimentos e pagamentos que fez por suas mãos a fl. 60 - $12.672 \$ 638$.

Do que deu ao S. Padre Superior das Missões por satisfação e para satisfazer algumas dividas antigas e modernas, embarques e fretes $-13268 \$ 065$.

[p. 07] Das contas deste Colégio com o do Maranhão. Colégio com Colégio até 1719.

Deve o Colégio do Maranhão a este fl. 16 - 3. 630, 192 cruzados. Do mesmo Colégio do Maranhão com a Procuradoria das Missões que este tomou a sua conta do ano de 1718 e 1719 para satisfazer uma dívida a José da Silva de Mesquita, em [sale], por não deixar esta dificuldade ao Padre Superior novo para o que também apliquei mais alguma outra dívida a Procuradoria do tempo que a servi.

Deve o dito Colégio a este pela Procuradoria o de fl. 30 - 1.841, 910 cruzados.

Deve este Colégio pela Procuradoria das Missões que exercitei, [?] do Prior do Maranhão - fl. 22. [pág. 02] - 1438, 256 cruzados.

Não consta ainda de todos os dispêndios do Colégio nestes anos, nas do [?] consta de dispêndios - 267722, 848 cruzados.

Consta também [?] verbas anotadas no $1^{\circ}$ fls. 60. 61 e 62 . e fls. 59.96.97, ter-se satisfeito das dívidas antigas - 4803, 688 cruzados os quais entram na mesma soma - 26722 cruzados.

Consta mais, que o Colégio há de haver no excesso das mesmas verbas de um conto, trezentos e setenta mil.

Cem [?], e [?] conto novecentos e doze mil quinhentos e setenta e oito - 542,478 cruzados. De 12: 672 \$ 698 - satisfeitos com 13: 268 \$ 265 - $525 \$ 421$. De 332 [?] \$ 675 - satisfeitos com - $3.636 \$ 292-307$ \$111. De 1.452 \$ 256 - satisfeitos com - 1.841 \$ $970-395$ \$ [?] 24 . O que tudo importa $-1.840 \$ 746$.

Capítulo 12 Das dívidas expressas destes anos a pessoas de fora não satisfeitas falando do que ainda resta de dívidas antigas não satisfeitas

A Francisco [?] [?]. 58 \$ 720.

A Manuel de Barros e Sylva de [?] de [?] .26 \$ 150.

A [?] Alves de [?] ano [?] .160 \$ 000.

Ao Fisco Real pelos servos e gados de [?]. $200 \$ 000$.

Soma - 434 \$870. 
Não me lembra mais porque o mais foi tudo encomendado ao Senhor Procurador das Missões por eu lhe não poder atender.

Capítulo 13o Das dívidas que devem ao Colégio

Bento Gomes Correia por ajuste de contas - 724\$ 000 .

Simão da Cunha de Sá por um crédito - $215 \$ 000$.

[p. 08] Diogo Reis Pereyra - 26 \$ 000.

O Padre Vigário da Vigia Francisco Estelim por um crédito - 50 \$ 000.

Estevão de Albuquerque do Camutá [Cametá] - 30 \$ 000.

O Padre Jorge da Gama, Missionário do Guaricurú - 21 \$ 000.

O Padre Felipe de Souza M. dos Tapajós - 24 \$ 000.

O Padre Manuel da Motta M. do Maracanã - $65 \$ 000$.

O capitão Mor Demetrio Dias de Tapuytapera $16 \$ 000$.

João Maciel Parente um crédito 68 \$ 000.

Vidal Maciel Parente por ajuste.

O Capitão Mor do Gurupá Fernando Lobo de Souza por um credito $80 \$ 000$.

$3252 \$ 56$.

Soma tudo 1250563 \$, com o que vem do Capítulo 11 de 1840 \$ 14 . Importa 292 \$3092. Não se faz menção dos dispêndios da Dispensa com farinhas algum peixe, das tartarugas, carne, galinhas, patos, [?], vinho da terra, azeites, e frutas, que gastaram a comunidade e servos assim por que não custaram dinheiro pelo darem as fazendas, ou de esmolas como por não haver quem pusesse estas coisas em seu lugar, como era bem, nem pelas fazendas destituídas contadas com clarezas que eram necessárias, sobretudo meu pouco talento e negligências divertida com tantas impertinências.

\section{Considerações finais}

O objetivo deste trabalho, ainda em fase inicial, está em primeiramente trazer a transcrição do Catálogo. E, depois, em identificar as passagens do documento que tratam da aparência da Igreja e do Colégio, ou seja, da arquitetura e da ornamentação destes monumentos, buscando ligações com o acervo remanescente.

As informações contidas neste Catálogo podem trazer muitas novas possibilidades para o tema da arte e da arquitetura nas missões jesuíticas do Grão-Pará, especialmente se soubermos analisá-las e coordenálas com outros documentos primários, e com bibliografia adequada. 


\section{Imagens da Documentação: O manuscrito do Catálogo do Colégio Jesuítico de Santo Alexandre em Belém do Grão-Pará (1720) da Coleção Lamego do arquivo do Instituto de Estudos Brasileiros da Universidade de São Paulo (IEB-USP)}

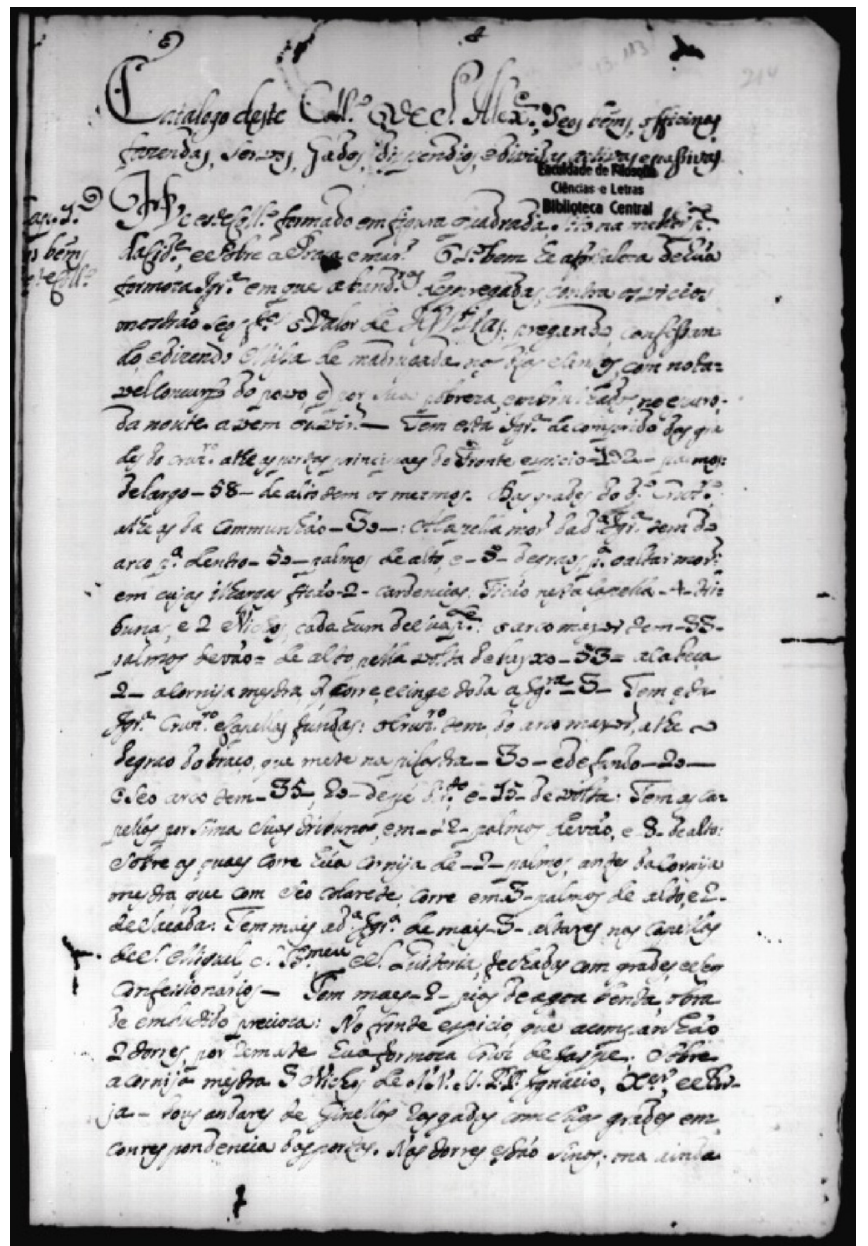

Figura 01: Manuscrito do Catálogo de 1720, folha 01. Fonte: Arquivo do Instituto de Estudos Brasileiros da Universidade de São Paulo (IEB-USP). MANUSCRITO DO CATÁLOGO DESTE COLÉGIO DE SANTO ALEXANDRE, seus bens, oficinas, fazendas, servos, gados, dispêndios, e dívidas activas e passivas. [ca. 1710], 8 p., documento 1.320, códice 43-113, p. 04. 


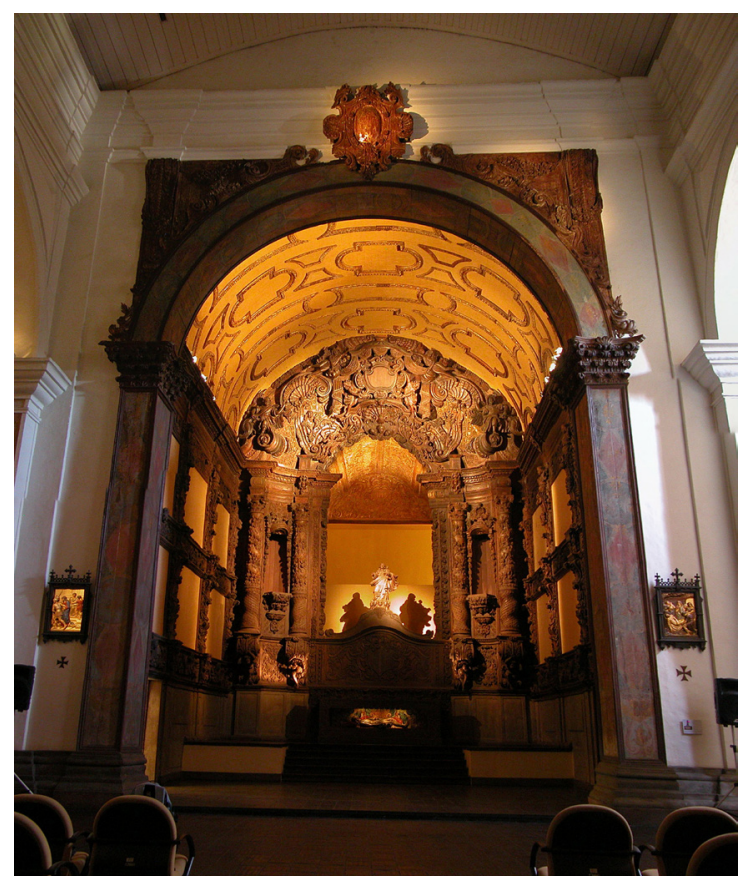

Figura 02: Capela-mor da Igreja de São Francisco Xavier. Fonte: Ricardo Hernán Medrano, agosto de 2007.

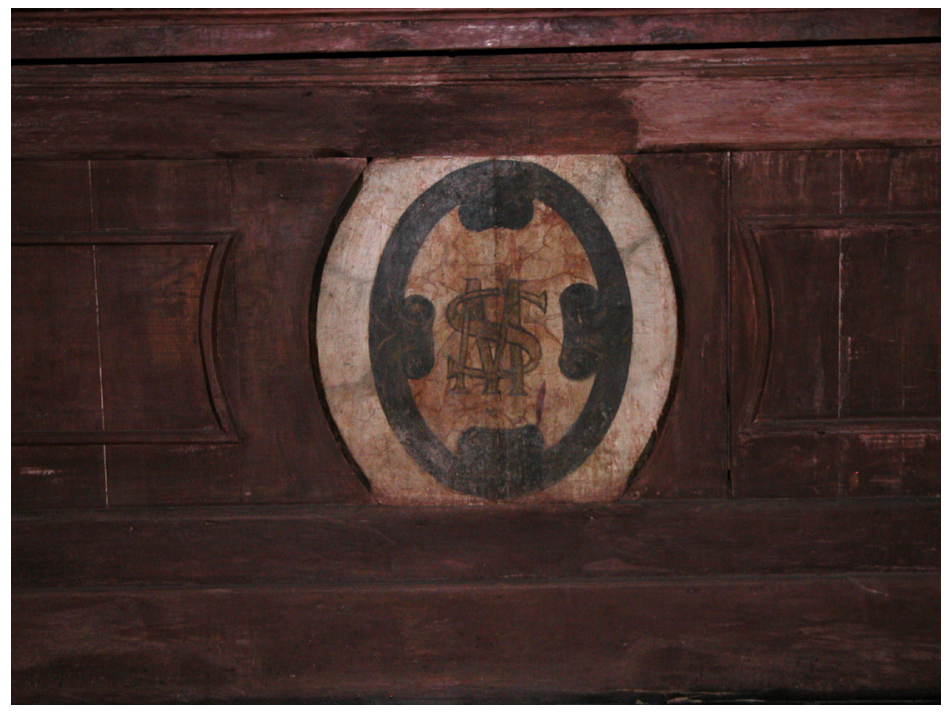

Figura 03: Monograma "SM" na mesa do altar da primeira capela lateral, lado da epístola, podendo indicar que o altar seria sagrado a "São Miguel". Fonte: Ricardo Hernán Medrano, agosto de 2007. 


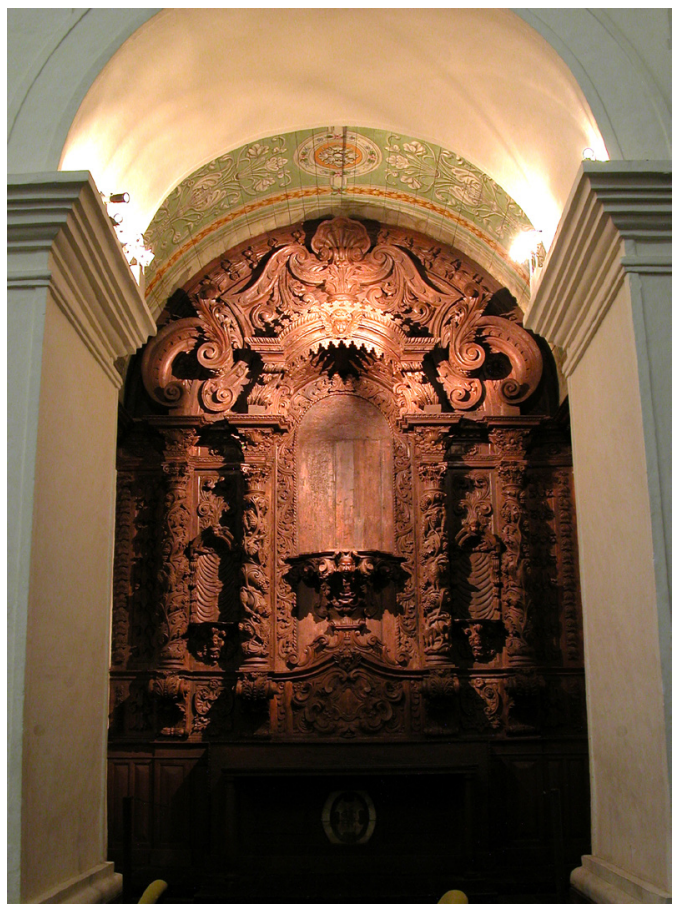

Figura 04: Altar com monograma “SM”. Fonte: Ricardo Hernán Medrano, agosto de 2007.

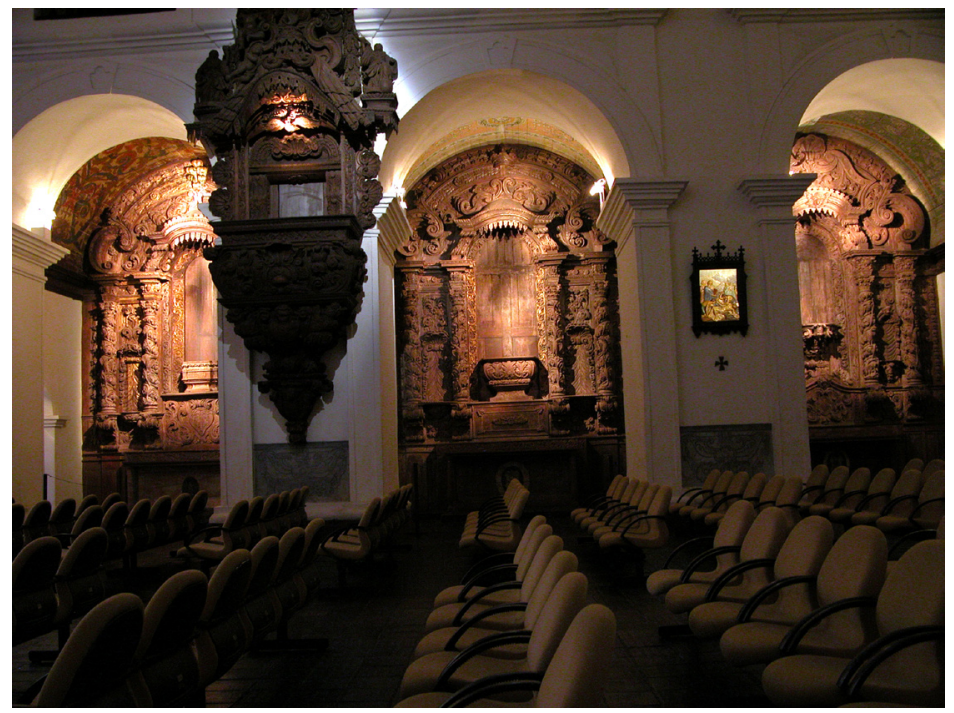

Figura 05: Capelas laterais do lado da epístola. Observar retábulos ainda conservados. Fonte: Ricardo Hernán Medrano, agosto de 2007. 


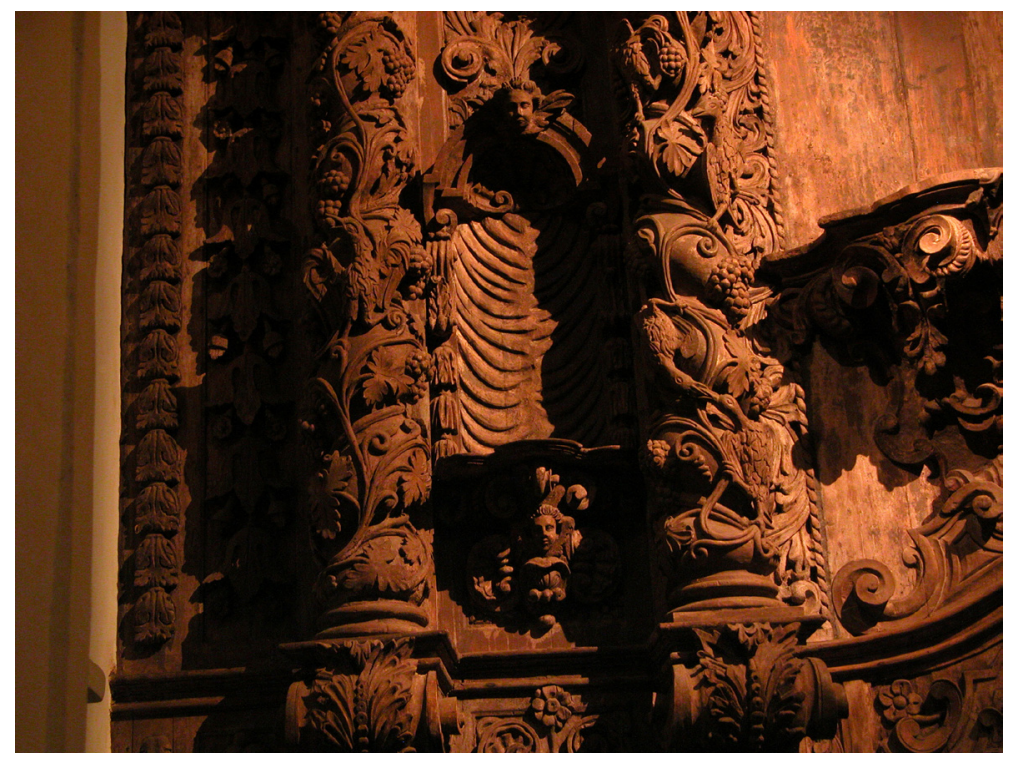

Figura 06: Nicho entre colunas de formas torças, com aves fênix e cachos de uva.

Retábulo da capela lateral do lado da epístola. Fonte: Ricardo Hernán Medrano, agosto de 2007.

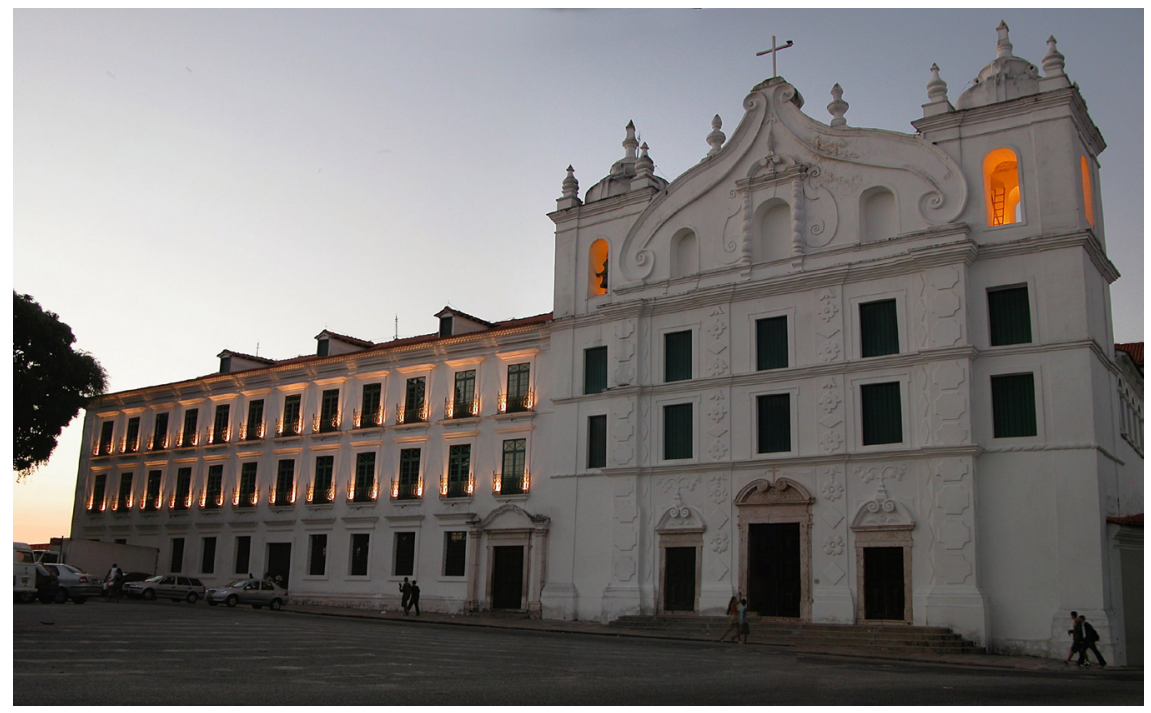

Figura 07: Fachada da Igreja de São Francisco Xavier e Colégio de Santo Alexandre. Fonte: Ricardo Hernán Medrano, julho de 2007. 


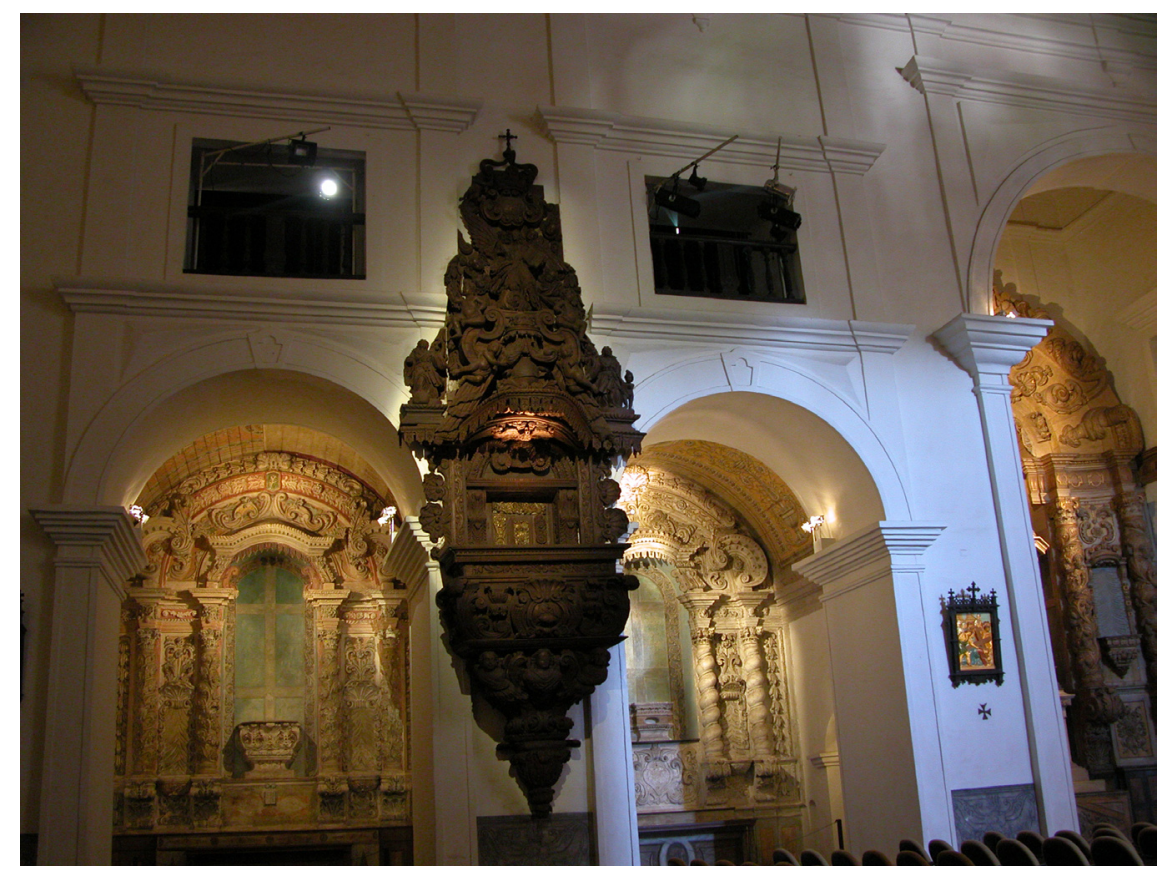

Figura 08: Púlpito da Igreja de São Francisco Xavier. Lado do evangelho. Fonte: Renata Maria Martins, agosto de 2007. 